\title{
DE LA "VIEJA" A LA "NUEVA" JUSTICIA INDÍGENA. \\ TRANSFORMACIONES Y CONTINUIDADES EN LAS JUSTICIAS \\ INDÍGENAS DE MICHOACÁN
}

Erika Bárcena Arévalo

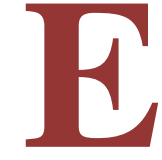

1 libro De la "vieja" a la "nueva" justicia indígena.

\section{Transformaciones} continuidades en las justicias indígenas en Michoacán, de Orlando Aragón Andrade (2016), analiza en términos generales el proceso de "oficialización de la justicia indígena" en la provincia de Michoacán, México, durante la primera década del siglo XXI. Para ello, entreteje distintas discusiones teóricas bien articuladas entre sí e incluso analíticamente propositivas, con una etnografía rigurosa del funcionamiento $\mathrm{y}$ organización de las justicias indígenas antes y después de las reformas judiciales que buscaron incorporarlas al aparato estatal de justicia.

En este sentido, son varios los aportes que la obra hace a la antropología jurídica y a los estudios sociojurídicos, entre los que destaca una lectura novedosa y bien sustentada del pluralismo jurídico. La antropología jurídica en México y la mayor parte de América Latina se ha centrado precisamente en las justicias indígenas y en su relación con el derecho estatal, y siendo un debate ampliamente discutido en la región, el aporte señalado no debe soslayarse.

El proceso de oficialización de las justicias indígenas redundó evidentemente en el objetivo de sacarlas de su contexto comunitario, lego desde el punto de vista del derecho estatal, para incorporarlas a la estructura del poder judicial en la entidad y, desde esta misma perspectiva, profesionalizarlas.
Para una mayor comprensión del campo al que se pretendió incorporar a las justicias indígenas, Orlando Aragón describe y analiza el aparato estatal de justicia de la provincia de Michoacán, lo que constituye una aportación de gran valía a la antropología jurídica puesto que se trata de la primera etnografía en México sobre tribunales estatales.

Pese a que desde la propia antropología se ha discutido la construcción cotidiana del derecho en procesos condicionados por $-\mathrm{y}$ condicionantes de-contextos sociales y culturales específicos, las prácticas propias de agentes estatales en estos procesos han merecido escasas líneas en los estudios etnográficos y por tanto es prácticamente nulo nuestro conocimiento al respecto.

Cabe señalar que si bien en Argentina y Brasil se ha desarrollado una corriente de la antropología jurídica que se centra en el estudio etnográfico de las instituciones de administración e impartición de justicia, principalmente cuerpos policiacos y tribunales en materia penal, lo cierto es que, al ser las justicias indígenas el objeto central de estudio, en el resto de la región esta corriente ha desarrollado en forma paralela sus propios conceptos, discusiones e incluso sus propias reflexiones metodológicas, sin que se haya establecido un diálogo con la antropología jurídica dominante.

Así, Orlando Aragón nos muestra por primera vez en su libro algunas de las prácticas y las dinámicas del Supremo Tribunal de Justicia de la Provincia de Michoacán, así como de 
los propios juzgados indígenas creados tras las reformas judiciales: el que atendería al pueblo purépecha, situado en la ciudad de Uruapan, y el que atendería al pueblo nahua, ubicado en la ciudad de Coahuayana.

Son múltiples los aspectos que analiza; sin embargo, por motivos de espacio me referiré brevemente a uno que considero particularmente importante. Según señala Orlando Aragón, el sistema de nombramiento de los juzgadores que existía antes de que se implantara una carrera judicial escalafonada y basada en sistemas de puntos (meritocrática), estaba regido por una lógica de relaciones interpersonales según la cual el gobernador de la provincia nombraba a los magistrados del Supremo Tribunal y éstos nombraban a los jueces menores, generalmente de entre el personal que laboraba en su tribunal. Así, particularmente en este último caso el capital relacional se combinaba con la noción que tenía el magistrado de que la persona seleccionada era apta para ocupar un puesto de juez por la competencia o el esfuerzo probado en la labor cotidiana.

Conforme a este mismo sistema de nombramiento el personal ascendía al interior de los tribunales en una especie de escalafón informal, de tal manera que como apunta Orlando Aragón “[...] también constituía $-\mathrm{y}$ lo sigue haciendo de otra manera- el mecanismo más efectivo para que el recién llegado al tribunal 'aprendiera', interiorizara y naturalizara la disciplina, el orden, la división jerárquica del tribunal, la mayoría de las reglas no escritas del STJE" (2016:106).

$\mathrm{Si}$ se analiza detalladamente se llegará a la conclusión de que una de las consecuencias de este sistema de nombramiento es que resulta uno de los mecanismos más eficaces de reproducción judicial: se trata de un proceso pedagógico de disciplinamiento que llevará a los funcionarios judiciales a reproducir más o menos acríticamente todo tipo de prácticas relacionadas con las formas "correctas" de estudiar y resolver los asuntos, y hasta con las formas "correctas" de entender los usos del derecho y la función jurisdiccional.

Sistemas de nombramiento similares se siguen reproduciendo, aún hoy día con una carrera judicial formal, en otros espacios. Orlando Aragón nos da la pauta en su libro para visibilizar prácticas que como éstas perfilan la impartición de justicia, y que finalmente tienen consecuencias concretas tanto a nivel individual para los justiciables como a nivel colectivo para las sociedades. Sin embargo, todavía queda mucho por observar y analizar en los espacios de impartición y administración de justicia, por lo que la agenda de investigación que nos deja la obra se torna también en sí misma un aporte significativo.

\section{Bibliografía}

ARAGÓN ANDRADE, Orlando. De la "vieja" a la "nueva" justicia indígena: transformaciones y continuidades en las justicias indígenas de Michoacán. México: Universidad Autónoma Metropolitana-Unidad Iztapalapa / Ediciones del Lirio, 2016. 